\title{
Comparative analysis of dynamic strength and impact toughness of pipe steels
}

\author{
Anatoly Bragov ${ }^{1 *}$, Alexander Konstantinov ${ }^{1}$, Andrey Lomunov ${ }^{1}$, and Leopold Kruszka ${ }^{2}$ \\ ${ }^{1}$ Research Institute of Mechanics, Lobachevsky State University, 603950 Nizhny Novgorod, Russia \\ ${ }^{2}$ Military University of Technology, Faculty of Civil Enginering and Geodesy, 00-908 Warsaw, \\ Poland
}

\begin{abstract}
To study the dynamic strength of pipe steels, a cycle of dynamic tests of three grades of pipeline steels (X80, X90, and X100) was performed, which included three types of experiments based on the Kolsky method: uniaxial tension of smooth specimens, as well as tension of specimens with a V-shaped annular notch and Charpy impact test according to the three-point bending pattern of beam-type specimens with a V-notch. In the last two cases, the fracture force and impact toughness, as well as the nominal fracture stress in the specimen, were determined. To assess the effect of "cold brittleness" and determine the temperature of the ductile-brittle transition, the specified test cycle was carried out in the temperature range from $+20^{\circ} \mathrm{C}$ to $-100^{\circ} \mathrm{C}$. As shown by the test results, the studied steels have a fairly high ductility: the elongation at break is 25$30 \%$. Therefore, the destruction of specimens directly in the first load cycle is not always possible. The use of an original system for registering additional loading cycles makes it possible to determine in which loading cycle the specimen ruptured. The limiting characteristics of plasticity $(\psi$ and $\delta$ ) of all tested steel grades are weakly dependent on both the strain rate and temperature (within the range of their variation). Whereas the impact toughness of steels significantly (2-3 times) decreases with a decrease in temperatures from room temperature to $-100^{\circ} \mathrm{C}$.
\end{abstract}

\section{Introduction}

It is known that the toughness of the metal of oil and gas pipelines (both the pipe body and welded seams) tends to decrease as the strength of the material increases; therefore, when developing new types of steel for high-pressure pipelines, it is necessary to evaluate the toughness of the material and especially its possible decrease in the case of negative temperatures (effect of cold brittleness) [1,2]. Trunk oil and gas pipelines in northern geographical latitudes are operated in difficult climatic conditions, namely, with outside air temperatures up to minus $60^{\circ} \mathrm{C}$.

A feature of the design of gas pipelines in the northern regions is the tightening of requirements for pipe material in terms of plasticity and viscosity. With a decrease in temperature, the strength characteristics of steel increase, however, the toughness and

\footnotetext{
* Corresponding author: leopold.kruszka@ wat.edu.pl
} 
ductility decrease. A certain difficulty is the choice of the required level of plastic and viscous properties. Therefore, when choosing a steel for work under these conditions, the determining indicators are: strength at the maximum operating temperature (room temperature) while toughness and plasticity - at the minimum temperature. Typically, the minimum operating temperature is determined by the tough-brittle transition temperature, at which the toughness of the steel drops to unacceptably low values, which is unacceptable for high-pressure pipelines. At present, during acceptance tests of metals and alloys for structures with a higher degree of reliability, standard Charpy tests are carried out to determine the impact toughness on beam-type specimens with a V-type concentrator (radius of curvature $0.25 \mathrm{~mm}$ ).

Russia has developed technologies for melting and rolling strip steel of categories X80, $\mathrm{X} 90, \mathrm{X} 100$ for the production of welded single-seam pipes of large diameter. The purpose of this work is a comparative study of the dynamic properties of three grades of pipe steel, differing in strength, plastic and viscous properties, and an assessment of the change in these properties at negative temperatures.

\section{Test methods and equipment}

A cycle of dynamic tests of three grades of pipe steels (X80, X90, and X100) was carried out, which included three types of experiments implementing modifications of the Kolsky method: uniaxial tension of smooth specimen (Fig. 1a) with obtaining stress-strain curves and determining the ultimate strength and deformation characteristics, as well as tension of specimens with V-shaped annular notch without fatigue crack (Fig. 1b) and Charpy impact test according to the three-point bending scheme of beam-type specimens with a $\mathrm{V}$-shaped notch, also without fatigue crack (Fig. 1c). In the last two cases, the fracture energy $K V$ was determined as the area under the curve $P(\Delta \ell)$, and the impact strength $\mathrm{KCV}$, as well as the nominal breaking stress in the specimen.

a)

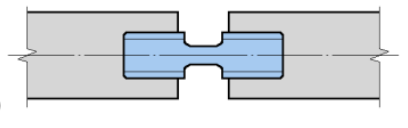

b)

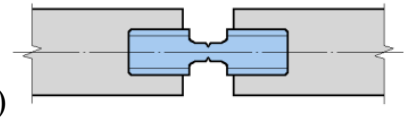

c)

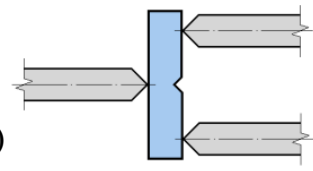

Fig. 1. Testing schemes of specimens.

To implement the first two types of tests (Fig. 1a-b), a gas gun with a tubular impactor was used, which allows to excite a tensile stress pulse in a split Hopkinson bar (SHB). Using the traditional formulas of the Kolsky method [3], the stress-strain curve $\sigma(\varepsilon)$ is obtained in these tests using the pulses of elastic deformations in the measuring bars, and then the conventional yield stress $\sigma_{Y}$ and the ultimate tensile strength $\sigma_{U}$ (stress at which a neck begins to form in the specimen) are determined. In the first case, the limiting characteristics of plasticity $\delta$ and $\psi$ are additionally determined. In the case of tension, a specimen weakened by an annular notch, the value of the nominal stresses $\sigma_{n}(t)$ is determined as the ratio of the force $P(t)$ developed in the specimen, measured in a transmitting pressure bar, to the cross-sectional area of the specimen in the notch $A_{0}$. Since the test specimens did not have a fatigue crack, in this series of tests, there was determined the fracture energy $K V$, as the area under the curve $P(\Delta \ell)$, and the impact toughness $K C V=K V / A_{0}$.

To implement the third type of test (Fig. 1c), a gas gun with a solid striker was used, which allows the excitation of a compressive stress pulse in the incident pressure bar. The latter scheme uses one incident and two transmitting bars with specially machined ends (sharpened onto a wedge). 
It should be noted that due to the large ratio of the cross-sectional areas of the measuring bars and the working part of the specimen (12:1), most of the incident pulse is reflected from the specimen, reaches the impact end of the first pressure bar, reflects as the second wave, then loads the specimen second time, is reflected again, etc. Thus, the specimen is subjected to several cycles of tensile load with gradually decreasing amplitude. For reliable registration of additional loading cycles, the length of the transmitting bar must be greater than the length of the incident bar as many times as the number of cycles is supposed to be recorded [4]. With the existing configuration of measuring bars, undistorted registration of two loading cycles is possible. Since the steels under study have good ductility (the elongation at break reaches $20 \%$ ), if the energy of the loading pulse is insufficient, the fracture of the specimen occurs not in the first (main) loading cycle, but some subsequent one. The analysis of the recorded impulses makes it possible to estimate in which cycle the specimen fracture occurred.

To assess the effect of cold brittleness and determine the temperature of the ductilebrittle transition, the specified test cycle was carried out in the temperature range from $+20^{\circ} \mathrm{C}$ to $-100^{\circ} \mathrm{C}$. During testing at negative temperatures, the specimen is cooled with liquid nitrogen vapor.

\section{Materials and specimens}

Specimens of three grades of strip pipe steel of strength category X80, X90, and X100 were subjected to dynamic tests, the characteristics of which are given in Table 1.

Table 1. Mechanical properties of pipe steel.

\begin{tabular}{|l|c|c|c|c|}
\hline $\begin{array}{l}\text { Strength } \\
\text { category }\end{array}$ & $\begin{array}{c}\text { Yield stress } \\
\sigma,, \mathrm{MPa}\end{array}$ & $\begin{array}{c}\text { Ultimate strength } \\
\sigma_{U}, \mathrm{MPa}\end{array}$ & $\begin{array}{c}\text { Percent elongation } \\
\delta, \%\end{array}$ & $\begin{array}{c}\text { Impact energy at }-40^{\circ} \mathrm{C} \\
K V, \mathrm{~J}\end{array}$ \\
\hline $\mathrm{X} 80$ & 555 & 625 & 18 & 155 \\
\hline $\mathrm{X} 90$ & 625 & 695 & 17 & 140 \\
\hline $\mathrm{X} 100$ & 690 & 760 & 17 & 160 \\
\hline
\end{tabular}

Specimens of three types were subjected to tests (Fig. 1): for tensile tests, solid specimens with threaded heads and a working part with a diameter of $5 \mathrm{~mm}$ and a length of $10 \mathrm{~mm}$ were made; for the study of fracture toughness, cylindrical specimens were made with a working zone length of $10 \mathrm{~mm}$, a full diameter sections $-7 \mathrm{~mm}$, the diameter of the section weakened by the V-notch - $4 \mathrm{~mm}$, as well as beam specimens $65 \mathrm{~mm}$ long, 10x10 $\mathrm{mm}$ in cross-section and V-type concentrator (radius of curvature is $0.25 \mathrm{~mm}$ ).

\section{Results and discussion}

A cycle of high-speed tensile tests of pipe steel samples at strain rates from $\sim 500 \mathrm{~s}^{-1}$ to $\sim 2500 \mathrm{~s}^{-1}$ in the temperature range from $+20^{\circ} \mathrm{C}$ to $-100^{\circ} \mathrm{C}$ was carried out. To determine the stress-strain curves and the ultimate fracture characteristics of materials, the Kolsky method was used with the use of a split Hopkinson bar in tension. Based on the results of the tests carried out, the strength (conventional yield stress and ultimate strength) and deformation (relative elongation and relative contraction) characteristics of the specimens were determined by measuring their residual shape after rupture.

Figure 2 shows a comparison of the strength properties of the tested steels, and Fig. 3 shows their limiting characteristics of plasticity $\delta$ and $\psi$ depending on the temperature 
change. A slight increase in strength properties can be noted with decreasing temperature. The temperature dependence of the limiting plasticity properties is weak.

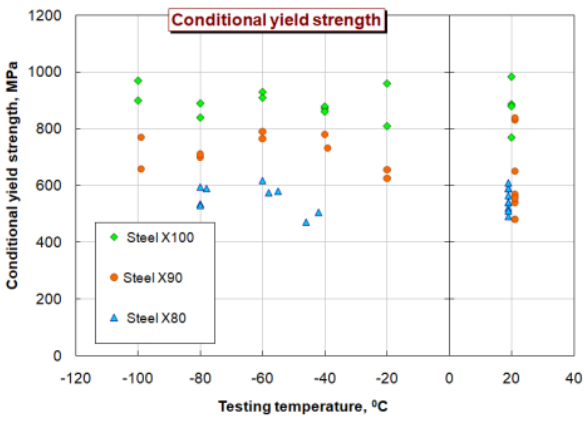

a)

Fig. 2. Comparison of strength characteristics: conventional yield strength (a) and ultimate tensile strength (b).

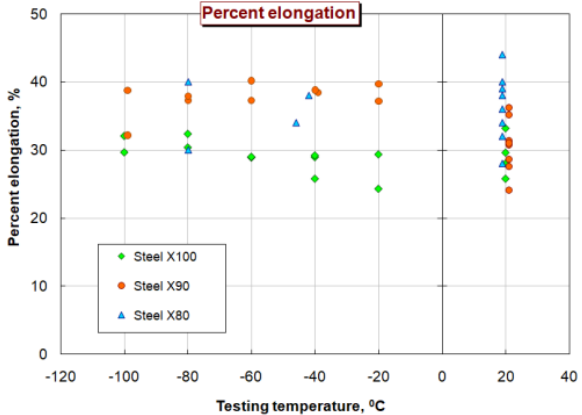

a)

Fig. 3. Comparison of ultimate deformation characteristics: percent elongation (a) and percent reduction in area (b).

The parameters of plasticity and strength characteristics of steels given in the figures were averaged. The obtained average values of these characteristics are shown in Table 2.

Table 2. Average strength and deformation properties of steels X80, X90 and X100 during tensile tests in the temperature range from $+20^{\circ} \mathrm{C}$ to $-100^{\circ} \mathrm{C}$.

\begin{tabular}{|c|c|c|c|c|}
\hline $\begin{array}{c}\text { Strength } \\
\text { category }\end{array}$ & $\begin{array}{c}\text { Yield stress } \\
\sigma_{Y}, \mathrm{MPa}\end{array}$ & $\begin{array}{c}\text { Ultimate strength } \\
\sigma_{U}, \mathrm{MPa}\end{array}$ & $\begin{array}{c}\text { Percent elongation } \\
\delta, \%\end{array}$ & $\begin{array}{c}\text { Percent reduction in area } \\
\psi, \%\end{array}$ \\
\hline $\mathrm{X} 80$ & 779 & 882 & 32.3 & 62.6 \\
\hline $\mathrm{X} 90$ & 787 & 1007 & 34.1 & 73.7 \\
\hline $\mathrm{X} 100$ & 890 & 1123 & 29.1 & 65.6 \\
\hline
\end{tabular}

One can note an increase in the average values of the conventional yield stress $\sigma_{Y}$ and ultimate tensile strength $\sigma_{U}$ of steel X90 compared to the average value of this parameter for steel X80 and an even greater increase in these properties for steel X100. There is no clear trend in the change in the limiting deformation characteristics of plasticity $\delta$ and $\psi$, depending on the steel grade.

To assess the tendency of structural materials to brittle fracture under shock loading, as an alternative to the standard impact test according to Charpy, a modification of the Kolsky tensile method and a specimen with an annular V-shaped notch were used in the work. The absorbed energy per unit area of fracture in these tests is taken as the energy characteristic of fracture - the so-called impact toughness $K C V$. Figure 4 shows the obtained critical 
(breaking) forces $P_{f r}$ and the values of the impact toughness of the tested steels depending on the test temperature.
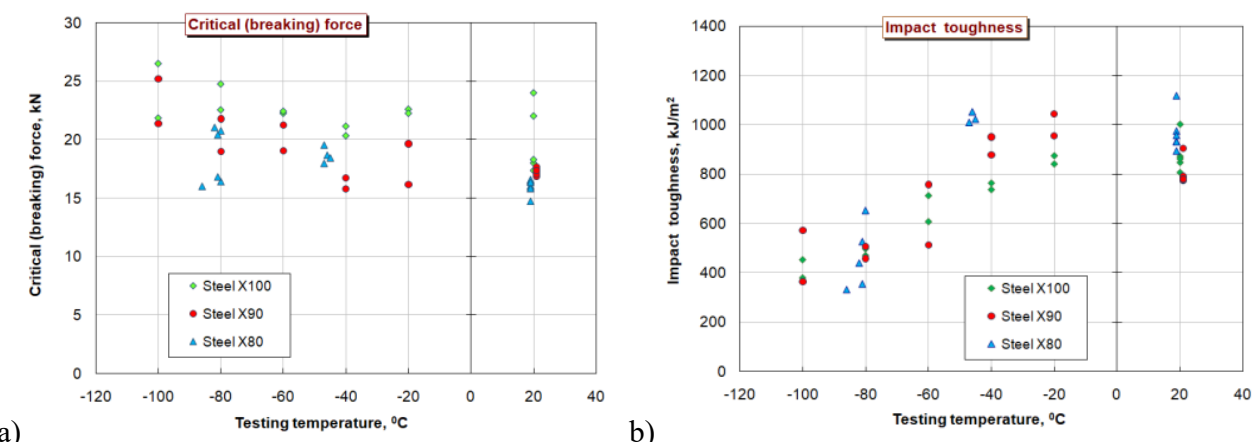

Fig. 4. Comparison of the critical forces (a) and impact toughness (b) of specimens with an annular V-notch under tension.

The effect of cold brittleness is clearly visible: the impact toughness $K C V$ for all steel grades decreases by more than two times when the temperature drops from $+20^{\circ} \mathrm{C}$ up to $-100^{\circ} \mathrm{C}$. At negative temperatures, one can see an increase in the average critical (breaking) forces in the specimens and a decrease in the impact toughness $K C V$ with an "increase" in the grade of steel. That is, the stronger X100 steel is more brittle: it has the lowest average (in the temperature range from $-50^{\circ} \mathrm{C}$ to $-100^{\circ} \mathrm{C}$ ) impact toughness.

As a result of a series of tests of these steel grades for three-point bending of beams with a V-notch in the temperature range from $+20^{\circ} \mathrm{C}$ to $-100^{\circ} \mathrm{C}$, as in the case of tensile tests of specimens weakened by an annular notch, the values of critical (breaking) forces and impact toughness $K C V$ were obtained depending on the test temperature. These values are shown in Fig. 5. Here, the effect of cold brittleness is also clearly visible: the impact toughness $K C V$ of steels $\mathrm{X} 90$ and $\mathrm{X} 100$ decreases by 3 times when the temperature drops from $+20^{\circ} \mathrm{C}$ to $-100^{\circ} \mathrm{C}$.
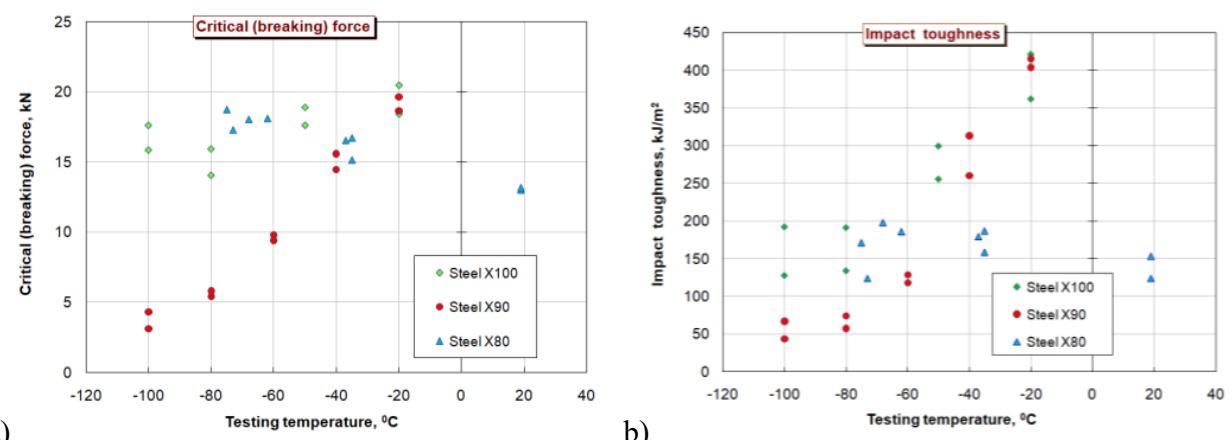

Fig. 5. Comparison of critical forces (a) and impact toughness (b) in beam specimens with a V-notch at three-point bending.

It is interesting to compare the parameters of the impact toughness of steels obtained on beam-type specimens at three-point bending and on solid specimens with an annular notch under tension (Figures $4 \mathrm{~b}$ and $5 \mathrm{~b}$ ). The difference in the values of the impact strength $K C V$ can be explained by the significantly different configuration of the tested specimens and different types of stress-strain state. It should be kept in mind that such tests give an assessment of the crack resistance of a particular specimen, and not a material, since it is assumed, as in the case of Charpy and Izod tests, that all the lost kinetic energy is spent on 
the formation of new fracture surfaces, neglecting the kinetic energy of parts of the destroyed specimen. In this regard, these tests, first of all, should be considered as comparative, allowing evaluating the effect of the initial state of the material on the tendency to brittle fracture, i.e. its toughness.

\section{Conclusions}

The tests carried out allow us to conclude that the strength properties of all steels slightly (by $20 \%$ ) increase at low temperatures compared to room temperature, the deformation characteristics are practically independent of temperature, the impact toughness of steels significantly decreases as temperatures drop from room temperature to $-100^{\circ} \mathrm{C}$ : $2-3$ times for steel X90 and 3 times for steel X100. Unusual results of measurements of the impact toughness of X80 steel on beam-type specimens indicate the possible uncontrollability of specimen cutting and notching (with respect to the rolling direction).

Experimental investigation of the strength and deformation properties of pipe steels was carried out with the financial support of the Russian Science Foundation (grant 21-19-00283). The study of the impact toughness of pipe steels was carried out with the financial support of the Ministry of Science and Higher Education of the Russian Federation (task 0729-2020-0054).

\section{References}

1. A.M. Bragov, A.Yu. Konstantinov, A.K. Lomunov, Yu.V. Petrov, A.V. Basalin, Procedia Structural Integrity, 13, 1811 (2018)

2. A.J. Krasowsky, Yu.A. Kashialyan, V.N. Krasiko, Int. J. Frac. 23, 297 (1983)

3. W.W. Chen, B. Song Split Hopkinson (Kolsky) Bar: Design, Testing and Applications. (Springer, New York, 2011)

4. A.M. Bragov, A.K. Lomunov, I.V. Sergeichev, J. App. Mech. Tech. Phys. 421090 (2001) 